\title{
Interest in Subject Matter: The Mathematics Predicament
}

\author{
Jerome I. Rotgans ${ }^{1} \&$ Henk G. Schmidt ${ }^{2}$ \\ ${ }^{1}$ National Institute of Education, Nanyang Technological University, Singapore \\ ${ }^{2}$ Erasmus University, Rotterdam, the Netherlands \\ Correspondence: Jerome I. Rotgans, National Institute of Education, Nanyang Technological University, 1 \\ Nanyang Walk, 637616, Singapore. Tel: 65-91-725-213. E-mail: rotgans@gmail.com
}

Received: July 3, 2014

Accepted: October 4, 2014 Online Published: November 13, 2014

doi:10.5539/hes.v4n6p31

URL: http://dx.doi.org/10.5539/hes.v4n6p31

\begin{abstract}
The present study sought to explore (a) the extent to which certain school subjects are perceived sui generis more interesting than others and (b) the extent to which students' interest in a subject is related to their study choices. A mixed-methods approach was chosen in which an individual interest questionnaire and an open-ended question were administered to 4,068 students at a polytechnic in Singapore. Data were analyzed by means of analysis of variance and content analysis of the responses to the open-ended question. The results suggest that mathematics courses were considered least interesting of all school subjects. Moreover, having to complete mathematics courses was responsible for a significant decrease in perceived interest for the entire study program the students were enrolled in. The content analysis revealed that students believe that mathematics is not in itself less interesting but that courses can be improved by providing more adequate learning resources and structure. Implications of these findings are discussed.
\end{abstract}

Keywords: mathematics, individual interest, text analytics, mixed methods research, subject domain differences, study choices

\section{Introduction}

\subsection{Background}

It is fair to say that everyone who went through formal education experienced some study subjects or disciplines as being less interesting than others. Although this seems to apply to most people, it constitutes a problem if there are too many subjects in the curriculum for which one lacks interest. In such case it can lead to adverse outcomes. For instance a student may have to alter his or her study direction or even drop out of school. In fact, current research suggests that a relatively large number of higher education students indicate-typically during their first year of study - that they lack interest and want to change or abandon their studies (Van der Veen, De Jong, Van Leeuwen, \& Korteweg, 2005). Needless to say that this constitutes a costly affaire for both the student and the instruction in terms of lost time, study fees, and general disappointment. Despite the emerging literature highlighting this potential problem, there are surprisingly few studies that investigated (a) whether some study subjects are typically perceived as being less interesting, and (b) why students lack interest in these study subjects. The objective of the present study was to find answers to these questions.

\subsection{Methodological Challenges}

A major reason for the limited number of studies examining why students lack interest in some study subjects seems to be related to methodological challenges to adequately compare between subject domains. For instance, Wolters and Pintrich (1998) and Vermetten, Lodewijks, and Vermunt (1999) cautioned that measured educational differences between various subject domains may not be so much due to the nature of the subject itself, but rather to differences in the instructional approach to these subjects. If for one subject the instructional method is small-group work and for another subject the instructional method is lectures, then differences in terms of interest cannot unequivocally be ascribed to the different subjects studied because they also can be caused by differences in instructional method. Because of this potential risk in misinterpreting interest data, it is suggested that if one wishes to conduct comparisons among school subjects one has to assure that both subjects are taught through the same didactics. This, however, has proven to be rather difficult because teachers have generally the liberty using any didactical approach they see fit for their course. Moreover, a teacher may choose to vary the didactical approach on a lesson-to-lesson basis (e.g., for one topic a lecture may be more suited and for another 
small group discussions). In short, it is difficult to control for different didactics applied by different teachers in different courses when conducting comparison studies. With the present study we addressed this issue and only compared courses that were taught using the same didactics.

\subsection{Literature on the Alignment between Study Choices and Interest}

The extent to which students' study choices are aligned with their interest, has received slightly more attention in the literature. A number of studies examined students' interest and disciplinary choices in university and vocational education. For instance, Mikkonen, Heikkila, Ruohoniemi, and Lindblom-Ylanne (2009) conducted a qualitative study with students from three different fields, arts, law, and veterinary medicine. During the first-year orientation program they asked the students to respond to the question "Why did you choose to study your main subject?" The answers were analyzed using content analysis, in which answers were manually coded and categorized in two broad categories "interest in the field of study" and "future work". The results revealed that in all three programs, $60 \%$ of the students mentioned interest as a major reason for their disciplinary choice. Overall, $38 \%$ of the responses referred to future work as a motive for enrolling in the programs. Some differences in response frequency were however observed between the three programs. Arts students stated that their main motive to choose for their discipline was due to the interest in the field of study and referred little to future work, whereas for the law and veterinary medicine students the reverse was the case. This study suggests that there are at least two motives that influence a student's disciplinary study choice. On the one hand, students' general interest in the field of study seems to be a factor and on the other hand future work may play a role.

Although the study provides insights into the motives for students' disciplinary choices (i.e., the reasons why they chose their study), the researchers did not empirically investigate what happened once the students were enrolled. It is possible that once students experience their study, they realize that their study choice is not entirely aligned with their interest. For instance, a student who wants to become a veterinarian all her life because she grew up on a farm with many animals and is interested in animal physiology enters the first year of university to find herself in basic science classes, covering chemistry, biology, and physics. This may cause a disappointment because the student perhaps expected to work with animalsand be trained in understanding animal diseases. This misalignment between one's expectations and the actual curriculum seems to be rather commonplace in higher education. For instance, large-scale student opinion surveys in the Netherlands have repeatedly demonstrated that students' interest in their chosen subject significantly decreases during the first year of study (Hofman et al., 2001). Interestingly, this was shown to be less the case for students in the second and higher years.

But why would there be a significant decrease in interest during the first year as demonstrated by the Hofman et al. study? Researchers have suggested that this decrease in interest during the first year is indeed most likely due to a subgroup of students realizing that they have chosen the wrong program of study. Support for this explanation is provided in a large-scale longitudinal study from Van der Veen et al. (2005). The authors suggest that a decrease in interest during the first year is due to feeling dissatisfied with the study choice, having low confidence that one will successfully graduate, and a lack of value and pride with regard to the future profession.

Although the results of the study suggest that misalignment between students' study choices and their personal interest may emerge over time, the study does not explain why students' interest slips away. Is it simply a matter of having chosen the wrong study from the onset, as Van der Veen et al. (2005) suggest, or are there other reasons?

\subsection{The Present Study}

We propose here that there is a possibility that the perceived misalignment in the first year is due to the fact that students in many educational programs have to complete first-year mandatory courses that are not perceived as relevant to students' longer-term professional goals and are violating students' expectations. The idea behind having to complete these mandatory courses is that students need foundational knowledge to be able to cope with more complex knowledge in the higher-year advanced courses. Although the idea makes sense from an educational perspective, the mandatory courses may convey the wrong message to students. Since these courses are generally foundational, typically covering topics such as basic sciences or mathematics, they may not be perceived as representative of the study program students enrolled for, and may therefore convey the impression to the students that the study program is all about mathematics or science. In summary, we propose that the misalignment problem of study choice and course interest during the first year is due to the fact that students have to complete mandatory courses that give them a false impression of the nature of their actual study program.

To test our hypothesis we identified three research questions that have the potential of casting more light on the issue. The first question is: "To what extent are students less interested in first-year mandatory courses as 
compared with subsequent courses that are more representative of their study choice?" If our hypothesis is true, students' interest should be lower for these mandatory courses. As a consequence, their level of interest should increase once they have completed the mandatory courses, which, in most curricula, is typically the case from the second year onwards. We therefore predicted that first-year courses are perceived as less interesting than subsequent courses. If this proves to be the case it would indicate that the misalignment between study choice and interests as noted by other researchers is indeed related to the first-year mandatory courses.

A second research question is about the first-year mandatory courses themselves: "Are there systematic differences in individual interest among first-year mandatory courses?" Theoretically, one would expect that individual interest in the mandatory courses varies largely among students-some students have a preference for subject $\mathrm{A}$ and $\mathrm{B}$ while other prefer $\mathrm{C}$ and $\mathrm{D}$ - and therefore no systematic differences in individual interest among mandatory courses are to be expected; different individual interests should cancel out any systematic differences. If this is however not the case, it would suggest that students generally have preferences for some mandatory courses above others. This in turn would help to identify which mandatory courses are potentially problematic and responsible for the perceived misalignment.

The final research question is related to a third important factor that needs to be verified; potential differences between the courses that constitute the diploma programs:"Are there systematic differences in individual interest among the higher-year diploma courses?" One could assume that once students are enrolled in their diploma program of choice no systematic differences are to be expected between different diploma programs in terms of the level of interest that students report. If the data would indicate that there are differences between diploma programs in terms of individual interest it would imply that some of these diploma programs are less aligned with what students expect them to be.

To find answers to the three research questions, we administered an interest self-report measure to 4,068 students at a polytechnic in Singapore. In this polytechnic, all courses use the same instructional method and assessment system, enabling direct comparison between course subjects. Moreover, at this polytechnic student have to complete several mandatory first-year courses, not necessarily directly related to their subject of choice. These courses comprise the more traditional mathematics, philosophy, and science foundation courses, but also more recently added courses aimed at improving communication skills and enterprise skills.

Our research strategy comprised of a mixed methods approach (Creswell, Plano Clark, Gutmann, \& Hanson, 2003; Greene, Benjamin, \& Goodyear, 2001) in which we combined quantitative and qualitative methodologies. To answer the three research questions we resorted to cross-sectional quantitative survey methods, and to gain more insights in the reasons why students preferred some courses to others, we conducted acontent analysis of open-ended responses. Considering the large scale of the sample of more than 4,000 participants that precluded reliable manual coding of student responses, we used an automated approach using state-of-the art computer-based text analytics (SPSS, 2006, 2008).

\section{Method}

\subsection{Participants}

The sample consisted of 4,068 participants ( $53 \%$ female and $47 \%$ male) with an average age of 19 years $(S D=$ 1.54). At the moment the sample was taken, the participants were enrolled in 148 courses in various diploma programs at a polytechnic in Singapore. The diploma programs the participants were enrolled in were five three-year programs: Engineering, Applied Sciences, Information Technology, Arts, and Hospitality.

\subsection{Educational Context}

In this polytechnic, the instructional method is problem-based learning (PBL) for all its courses and programs. In this approach five students work together in one team under the guidance of a tutor. Each class comprises four to five teams. Unique to this polytechnic's approach to PBL is that students work on one problem during the course of each day (Choo, Rotgans, Yew, \& Schmidt, 2011; Rotgans, O’Grady \& Alwis, 2011; Sockalingam, Rotgans, $\&$ Schmidt, 2011). This means that students deal with one problem each day in all courses. A typical day starts with the presentation of a problem. Students discuss in their teams what they know, do not know, and what they need to find out. By doing so, students activate their prior knowledge, come up with tentative explanations for the problem, and formulate their own learning goals. Subsequently, a period of self-study follows in which students individually and collaboratively try to find information to address the learning goals (Hmelo-Silver, 2004; Schmidt, 1983, 1993; Schmidt, Van der Molen, Te Winkel, \& Wijnen, 2009). At the end of the day the five teams come together to present, elaborate, and synthesize their findings. In this polytechnic, a uniform assessment system is applied in which all students in all courses have to sit for written exams. There are three 
exams every four weeks in all courses. The assessment format is a combination of multiple-choice questions and open-ended questions.

All students in the polytechnic, independent of their diploma program, have to complete the mandatory first-year courses. In the second and third year they study their discipline-specific courses. Because the instructional approach and the assessment system are identical in setup throughout the polytechnic it was possible to directly compare levels of individual interest between the courses.

\subsection{Measures}

A measure of individual interest was devised as part of a regular program evaluation questionnaire that is administered routinely every semester. In our operationalization of individual interest we followed Schiefele (1992) distinction between the two components of individual interest: a value-related component, referring to the extent that students recognized certain topics as relevant for their future career, and a emotion-related component, indicating the extent to which they liked a particular topic. To measure the value-related component we devised two items: "The topics of this course seemed useful for my future professional practice" and "I have learned many useful things in this course." The items were scored on a 5-point Likert scale: 1 (not true at all), 2 (not true for me), 3 (neutral), 4 (true for me), and 5 (very true for me). In order to measure the emotion-related component we devised two items: "In general I enjoyed the course" and "The topics we addressed in the course were interesting." The construct validity of this short individual interest measure was established by means of confirmatory factor analysis (Byrne, 2001). The assumption was that all four items for each measure were manifestations of one underlying factor: individual interest. The results revealed that the data fitted this hypothesised model well. The $\chi^{2} / \mathrm{df}$ ratio was $3.72, p=.02, \mathrm{RMSEA}=.03$ and CFI $=1.00(N=4,068)$. All factor loadings were statistically significant and ranged from .69 to .79 , with an average of .74 . The reliability of the measure was determined by calculating Hancock's coefficient $H$ (Hancock \& Mueller, 2001). The coefficient $H$ is a construct reliability measure for latent variable systems that represents a relevant alternative to the conventional Cronbach's alpha. Hancock recommended a cut-off value for the coefficient $H$ of .70. The average coefficient $H$ for the individual interest measure was .84. Overall, these results demonstrate that the psychometric characteristics of the individual interest measure are adequate.

In addition to the items, participants responded to an open-ended question: "How can the course be improved?" We asked this broad question to allow students to report anything that they did not like about the course.

\subsection{Procedure}

The four items of the individual interest measure were included in a regular program evaluation questionnaire that was administered to 4,068 randomly identified students across 148 courses. The courses comprised five first-year mandatory foundation courses, viz. basic science, mathematics, philosophy, communication skills, and enterprise skills. The remaining courses were second- and third-year courses, which belong to the five diploma programs engineering, applied science, information technology, arts, and tourism. Examples of courses in these diploma programs include microbiology, advanced mathematics, laboratory management, waste water treatment, applied physics, diagnostic imaging, financial accounting, database systems, logical programming, logistic planning, aerodynamics, journalism. Students were randomly selected to fill in the program evaluation and it was made mandatory to respond to the questionnaire ( $92 \%$ response rate). The questionnaire was administered online and appeared in the students' regular electronic learning environment. Participants had one week to respond.

\subsection{Analysis}

Data were analyzed to answer each of the three research questions. All analyses comprised a one-way analysis of variance (ANOVA) with least significant difference (LSD) comparisons of the means. In addition to the $F$ - and $p$-values, the effect-size was calculated by means of eta-squared. Eta-squared represents the ratio of variance explained in the dependent variable by a predictor while controlling for other predictors. Generally, .10 is considered a "small" effect, .25 is considered a "medium" effect and $>.40$ is considered a "large" effect (Cohen, 1992).

To address the first research question (To what extent are students less interested in first-year mandatory courses as compared with courses that are more representative of their study choice?) we tested whether there were mean-level differences in individual interest between the first- and higher-year courses. The independent variable was study year and the dependent variable was individual interest. Since the higher-year courses were expected to be more closely aligned with the students' study choices, we expected to find significantly higher levels of individual interest for these courses as compared to the first-year mandatory courses.

To test the second research question (Are there systematic differences in individual interest between first-year 
mandatory courses?) we examined whether there were mean-level differences in individual interest between the first-year mandatory courses. The independent variable was first-year foundation courses and the dependent variable was individual interest. Since the first-year courses are all mandatory, we expected to find no significant differences in individual interest between these five courses because students' individual interest in the mandatory courses may largely vary, cancelling out any systematic mean differences.

Finally, to address the third research question (Are there differences in individual interest between the higher-year diploma courses?) we examined whether there are mean-level differences in individual interest between the higher-year diploma programs. To conduct the analysis we used the aggregate of all courses that belong to each of the five diploma programs. The independent variable was diploma program and the dependent variable was again individual interest. We expected to find no differences in individual interest among diploma programs since at this stage (i.e., the second and third year) students are enrolled in their programs of choice, which is presumably based on their individual interest.

In addition to the above analyses we conducted a content analysis of students' responses to an open-ended question to further examine why certain subjects - if any - areperceived as less interesting. The responses were analyzed using linguistics-based text analytical technologies applied by the SPSS Text Analysis for Surveys ${ }^{\mathrm{TM}}$ 2.1 software (SPSS, 2006). The software uses advanced linguistic technologies that extract and classify key concepts from the responses. Using these technologies, the content is analyzed as a set of phrases and sentences whose grammatical structure provides a context for the meaning of a response. The software enables the coding and categorization of responses in a fraction of the time required when doing it manually. More important, the categorization of responses is done consistently and reliably (SPSS, 2008). Unlike human coders, the software classifies the same concepts in the same categories every time. The first step of the content analysis is to extract key terms from the responses. The software uses linguistic algorithms to identify relevant concepts based on libraries that contain pre-coded definitions. This means that the extraction does not treat a response as a set of unrelated words, but it identifies key words, compound words, and patterns in the text. As a next step in the content analysis, the extracted terms are grouped by the software into categories that form the basis for further analyses. A category refers to a group of closely related concepts, objects, or opinions.

The software applies three linguistic techniques that take the meanings of the extracted terms and their inter-relationships into account: (a) term derivation, (b) term inclusion, and (c) semantic networks. Since these techniques complement each other, all three are used for the categorization of the extracted terms (SPSS, 2006). The term derivation technique forms categories by analyzing if any of the terms are morphologically related, for instance, the term "self-concept" and "concept of the self" would be grouped in the same category. The term inclusion technique uses algorithms to create categories by taking a term and finding other terms that can be included. For instance, the terms "learning resources", "study resources", "resource materials", "learning resource materials" would be grouped under the root term "resources." As such, "resources" forms a category, which includes the root term "resources" and all word combinations before it, after it or both. The semantic networks technique forms categories using a semantic/lexical network, which is based on WordNet ${ }^{\text {(Miller, }}$ 1995). WordNet ${ }^{\circledR}$ is a large lexical database of English developed by Princeton University. Nouns, verbs, adjectives, and adverbs are grouped into sets of cognitive synonyms (synsets), each expressing a concept. The created synsets form the basis of a category.

In order to analyze the responses to the open-ended question, the mean and standard deviations of the frequency counts for each category were calculated. An independent samples $t$-test was then used to analyze whether there are significant differences in the mean categorical values between the mathematics and none-mathematics courses. In addition to the $t$ and $p$-values, Cohen's $d$ was computed as a measure of effect-size. Cohen's $d$ is an effect size used to indicate the standardized difference between two means. Generally an effect size of .20 to .30 is considered "small", around .50 is considered "medium" and >.80 is considered a "large" effect (Cohen, 1992; Salkind, 2010).

\section{Results and Discussion}

To address the first research question it was examined whether higher-year courses are perceived as being more interesting than the first-year mandatory courses. Since the higher-year courses are supposed to be more closely aligned with students' study choices, we expected that students' individual interest pertaining to these courses would be significantly higher than the mandatory first-year courses. This test would thus clarify whether the mandatory courses are indeed responsible for the perceived misalignment of study choice and course interest during the first year. The results of the ANOVA revealed that there was a non-significant main effect: $F(1,3226)$ $=.98, p=.32$, eta-squared $<.01\left(M_{1 \mathrm{st} \text { year }}=3.89, M_{2 \mathrm{nd} \& 3 \mathrm{rd} \mathrm{years}}=3.85\right)$. Contrary to what we hypothesized, this 
preliminary outcome suggests that students are not necessarily less interested in the first-year mandatory modules.

A possible explanation for the non-significant mean differences that some more interesting mandatory courses (e.g., enterprise skills) may have been so interesting that they have more than canceled out the less interesting or less popular courses (e.g., science and mathematics) resulting in a higher mean score, which is non-significantly different from the higher-year courses. This possibility was examined by testing the second research question for which we conducted a more detailed analysis of the mean-level differences in individual interest between the first-year mandatory courses of science, mathematics, philosophy, communication skills, and enterprise skills. The results of the ANOVA suggest that there was significant main effect $F(4,235)=9.01, p<.01$, with a relatively small effect size (eta-squared $=.10$ ). The post hoc pairwise comparisons revealed that students' individual interest for mathematics was reported significantly lower compared withallof the other four subjects $(p<.01)$. See Table 1 for the mean values and standard deviations of students' individual interest for each of the five first-year mandatory courses.

Table 1. Descriptive statistics for the mean differences in individual interest between the five first-year mandatory courses

\begin{tabular}{lll}
\hline Subject & Mean & SD \\
\hline Basic science & 3.78 & .63 \\
Mathematics & 3.51 & .75 \\
Philosophy & 3.94 & .60 \\
Communication skills & 4.19 & .59 \\
Enterprise skills & 4.02 & .64 \\
\hline
\end{tabular}

Individual interest for the communication skills subject was rated significantly higher than for basic science $(p<.01)$ and mathematics $(p<.01)$. A follow-up analysis revealed that individual interest for mathematics was indeed significantly lower than interest for the higher-year courses $(p<.001)$. This outcome suggests that only mathematics as mandatory first-year course is perceived as significantly less interesting; the other mandatory courses are not that much different from the higher-year courses. In light of these findings we have to redefine our leading hypothesis: the misalignment between study choice and course interest in the first year of study seems to be due to only one subject: Mathematics. We will return to this issue later on.

To test the third research question we examined to which extent there are mean differences in individual interest between the diploma programs. Since all students are enrolled in their diploma program of choice, we did not expect to find any differences in individual interest between them. The outcome of the analysis however suggests that this is not the case. The results of the ANOVA revealed that there were significant differences in individual interest among the higher-year diploma programs, $F(4,2983)=10.23, p<.0001$. Although the results were statistically significant, the effect size was rather small (eta squared $=.014$ ) suggesting that the differences are relativelyminor. Nonetheless, the post hoc pairwise comparisons revealed that there are non-significant differences between Applied Sciences, Hospitality, and Arts, which form a cluster around $M=3.90$. The mean values of individual interest for the Information Technology and Engineering was, however, significantly lower $(p<.01)$ than the above cluster, with the mean for Engineering being significantly lower than for Information Technology. See Table 2 (first two columns) for the descriptive statistics. 
Table 2. Descriptive statistics for the mean differences in individual interest between the five diploma programs

\begin{tabular}{lll}
\hline Subject & Mean (SD) & $\begin{array}{l}\text { Mean (SD) without } \\
\text { Math-related courses }\end{array}$ \\
\hline Applied science program & $3.91(.60)$ & $3.91(.60)$ \\
Engineering program & $3.75(.65)$ & $3.90(.60)$ \\
Information technology program & $3.84(.62)$ & $3.86(.61)$ \\
Hospitality program & $3.93(.64)$ & $3.93(.64)$ \\
Arts program & $3.94(.63)$ & $3.94(.63)$ \\
\hline
\end{tabular}

This outcome suggests that although students in these two programs are enrolled in the courses of their choice, they are not interested in their study programs to the same extent as arts, applied sciences, and hospitality students. This finding is rather surprising: How is it possible that students choose a particular diploma program (presumably based on their interest) but find it less interesting? And why is this only the case for Engineering and Information Technology and not for the other three courses?

The answer to these questions turns out to be linked to our earlier findings, which suggested that mathematics was perceived as being least interesting during the first year. Considering that the advanced mathematics courses were to be found exclusively in the Engineering program and the Information Technology program, it is possible that mathematics courses are responsible for the reported lower levels of interest. To test this hypothesis, we assumed that when excluding all mathematics courses from the analysis the result should reveal non-significant differences in individual interest between the five diploma programs. Out of a total of 111 courses, 24 courses could be identified as being directly related to mathematics and were excluded from the analysis. Examples of these mathematics courses are: advanced mathematics, logic programming, applied mathematics, sampling theorem, quantitative methods, data acquisition, ladder logic, and measurement techniques. After excluding the mathematics courses from the analysis, the main effect was not longer statistically significant, $F(4,2117)=1.49$, $p=.20$, eta squared $=.003$. See the last column of Table 2 for the mean values of individual interest for all five programs. This outcome suggests that the mathematics courses in these two diploma programs are most likely responsible for the overall lower levels of individual interest.

The findings so-far suggest that mathematics was not only responsible for the misalignment between study choice and course interestamong the first-year mandatory courses and between first and second year courses, but also for differences among the higher-year courses; as such, mathematics seems to be a "dissenting voice" across all programs. The question is then, why is mathematics perceived as less interesting across all diploma programs and courses? We addressed this question by means of the content analysis through which we analyzed students' improvement suggestions for all courses.

Remember that the open-ended question posed to students was: "How can the course be improved?" The content analysis of their answers resulted in the extraction of three key concepts: (A) Conceptual comprehension, consisting of subthemes like "theory", "knowledge", "understanding", and "principles." For instance, students mentioned: "Explain the theory in simple terms", "Since, I've not much prior knowledge about this moduleexcept from O levels, I found it hard to comprehend much of the concepts", or "Some formulas and working principles of the particular mechanism could be explained to us so that we can have a better understanding"; (B) Study management, consisting of subthemes like "more interacting classes", "practice", "guidance", and "time." For instance students stated: "The lesson should have more interaction between teacher and students", "There could perhaps be more hands-on sessions that will put our theories into practice", or "This module could be more focusedsince the problemsare very broad and there is insufficient time to deal with every aspect"; and (C) Learning support, consisting of subthemes like "resources", "worksheets", and "teachers." For instance, the students stated: "Provide better resources", "Provide more exercise worksheets together with worked solutions" or "It can be improved when the teacher is able to help the weaker students by going to their table to see their progress."

After extracting these concepts for each course it was tested whether there was a significant difference in the categorical frequency count between mathematics courses and all non-mathematics courses. Table 3 depicts the results of the independent samples $t$-test. 
Table 3. Results comparison frequency score between mathematics courses and all remaining second- and third-year courses

\begin{tabular}{llllcll}
\hline Concept & Course type & Mean & SD & $t$-value & $p$-value & Cohen's $d$ \\
\hline Conceptual & General & .12 & .32 & .77 & .12 & .06 \\
& Math-related & .10 & .31 & & & \\
\multirow{5}{*}{ Study management } & General & .20 & .40 & -.34 & .50 & .00 \\
& Math-related & .20 & .40 & & & \\
Learning materials & General & .28 & .45 & -4.49 & $<.01$ & -.23 \\
& Math-related & .39 & .49 & & &
\end{tabular}

The results revealed that there was a statistically significant difference in frequency count for only one concept: Learning support $(t=-4.49, p<.01)$ with a small effect size. The difference in categorical frequency count of the learning support category suggests that the mathematics courses, relative to other courses, fall short in providing sufficient support to help students learn. For instance, students stated that more supportive worksheets should be used in the mathematics courses: "a worksheet should be used for all lessons" and "answers to the worksheets should be provided at the end of the week" (15\% of all responses in the mathematics courses included the term "worksheet"). Instructional worksheets typically consist of questions and assignments, which provide students with structure and help them to work on a specific topic in a systematic manner (Choo, Rotgans, Yew, \& Schmidt, 2011). Students also frequently stated: "more learning resources should be provided" and "more examples should be provided in the resources" (41\% of all responses in the mathematics courses included the term "resource"). But also the teacher seems to play a significant role as a provider of information: "maybe the teacher can explain the terms to the students so that they would be able to understand better" and "the teachers should also recap of past lessons and help trigger students' thinking process" (47\% of all responses in the mathematics courses included the term "teacher"). The results of the content analysis imply that the low interest in mathematics courses seems not directly related to conceptual factors, such as difficulty level or abstraction level of mathematics concepts, or study management issues, but it seems related to instructional shortcomings, such as lack of guidance and structure.

\section{General Discussion}

The major objective of the present study was to investigate whether students' study choices are aligned with their individual interests - and if not, what causes this misalignment. This is an important educational matter since an increasing number of students seem to realize - in particular during the first year of study - that they have chosen a study program for which they lack interest (Hofman et al., 2001; Van der Veen et al., 2005). As a consequence, these students may have to switch study programs at the end of the first year or even dropout of school or university. We initially hypothesized that the misalignment is due to students having to complete first-year mandatory courses outside their domain of choice. We have argued that since these mandatory courses in the first year are often mathematics- or science-related they may convey the impression to students that their study program predominantly revolves around such subjects. To test this hypothesis we examined three research questions that cast more light on this issue: (a) "To what extent are students less interested in first-year mandatory courses as compared with courses that are more representative of their study choice?"; (b) "Are there differences in individual interest among first-year mandatory courses?"; and (c) "Are there differences in individual interest between the higher-year diploma courses?"

The results revealed that there were no significant differences between the mandatory first- and higher-year courses. As such, this outcome did not provide support for our primary hypothesis that the mandatory first-year coursesare per se responsible for the perceived misalignment during the first year. Further detailed analysis of the mandatory first-year courses themselves revealed that students' individual interest was only significantly lower for one particular course: Mathematics. This outcome suggests that only the mandatory mathematics course wasperceived as significantly less interesting compared to the other mandatory courses and thus may be responsible for a perceived misalignment in the first year. Subsequent analyses involving only the higher-year courses confirmed this observation; all higher-year mathematics-related courses were rated as significantly less interesting compared to all other courses. One has to realize that by the second year all students are in the 
diploma program of their preference, leading to the expectation that all diploma programs (all things being equal) will be found equally interesting. This turned out not to be the case; two diploma programs, namely Engineering and Information Technology were considered significantly less interesting, and we were able to demonstrate that this is because these programs contained manymathematics-related courses (24 in total). Removing the mathematics courses from the analysis resulted in non-significant differences in individual interest between the diploma programs, strongly suggesting that only the mathematics courses were responsible for the perceived misalignment between a students' study choice and individual interest in the higher-year programs.

The content analysis provided more detailed insights in the reasons why mathematics was perceived as relatively less interesting across all courses and years. When asked how the mathematics courses could be improved, students' main concern was that they did not receive sufficient instructional support; more examples, worksheets, and direct instruction by the teacher were mentioned most often as means to improve these courses. Surprisingly, students did not mention having conceptual problems with mathematics itself or difficulties related to study management. This seems to suggest that the active-learning PBL environment did anadequate job in presenting and embedding the rather abstract mathematics concepts in authentic problem scenarios students could relate to. Nevertheless, this positive instructional feature should have been combinedor "enriched" with more guidance and structure when students further worked on the problems in their small groups or during self-study.

\subsection{Contribution to the Higher Education Literature}

The above suggestion is in-line with recommendations made by researchers such as Ormell (1984) and Suraweera (1984) who propose that good mathematics education starts with a good structure and students should understand its value and application to other subjects and real life. More recently, many researchers and practitioners uttered the opinion that ICT can provide a viable solution to the mathematics problem. For instance, Viamonte (2010) suggest that computers should be used as tools to assist students in the exploration and discovery of mathematics concepts. Although there is some evidence that ICT can help students understand mathematics concepts better, it is still not clear whether ICT makes it also more interesting (Clements, 2002; Manoucherhri, 1998) and provides the necessary structure.

There is no doubt that mathematics is an important subject and cornerstone of many educational programs-in particular in higher education, such as in Engineering programs or the Sciences. However the reality is that many students perceive mathematics as the least interesting subject and a burden for their studies (Hannover \& Kessels, 2004; Schoon, 2001). Dealing with this predicament is not an easy task and it is questionable if ICT can indeed provide a comprehensive solution. The present study contributes to the higher education literature in two important ways. First, our findings are based on a large sample involving close to 150 different higher education courses in which all students were exposed to the same instructional approach. This enabled us to control for instructional influences and adequately comparedifferences that are due to the nature of the subject itself. To our best knowledge, this has never been attempted before and thus provides new insights in this important issue. Second, including open-ended responses and subjecting them to sophisticated text analytical analysis provided us with detailed insights (in addition to the quantitative data) as to what the underlying reasons are why mathematics programs are perceived as least interesting. Conducting this analysis on such a large scale has not been done before.

\subsection{Implications for Theory and Practice}

Based on the findings of the current study, we propose three instructional strategies that can make mathematics education more interesting and effective.

The first approach seeks to contextualize mathematics knowledge. The beauty of mathematics is that it provides tools to understand a large number of different phenomena in the world; it gives us a language to interpret these phenomena. Some authors maintain that its abstractness is both its strength and its weakness: it is necessarily abstract to be able to play its role, but its lack of reference to a concrete, real world makes it difficult to teach. Unlike a topic such as physics that refers to an observable material world, students cannot really imagine anything concrete with mathematic propositions. Therefore attempts have been made to embed mathematics teaching into concrete real life experiences (such as problems in PBL), an approach pioneered by Freudenthal (Freudenthal, 1968, 1973, 1981). This "realistic mathematics education" takes at its starting point everyday phenomena or events and teaches mathematical ideas and procedures in the context of these phenomena or events. Although it appeals to intuitive logic that this approach is more interesting for students to learn mathematics, empirical evidence is rather scarce (Gravemeijer \& Doorman, 1999). Moreover, critics maintain that mathematics requires a considerable amount of rehearsal in order to become adequately embedded in memory. In addition, they claim that using the realistic route, mathematics will never become the abstract tool in 
the mind of the learner it is supposed to become (Burns, 2005).

A second approach advocated by some is presenting students with worked mathematics examples (Atkinson, Derry, Renkl, \& Wortham, 2000; Renkl, 1999, 2002), similar to what students mentioned in their responses. The idea is that providing examples of how to solve mathematics problems will help students understand the underlying mechanisms and apply them to new contexts. However, a problem noticed by some researchers is that examples require many variables to be kept in working memory at the same time. This might lead to cognitive load to an extent that manipulation with these variables becomes difficult because of the limitations of working memory (Tarmizi \& Sweller, 1988). As such, worked examples should integrate all sources of informationinto one combined presentation (e.g., a complex diagram combined with aural explanations), since splitting students' attention across multiple, non-integrated informational sources (e.g., a diagram, a text, and aural explanations) may cause cognitive overload and impair learning. This is an important issue to remember when planning to implement ICT as an instructional tool in mathematics education. There is evidence that learning is fostered by worked examples (Atkinson et al., 2000) but presently evidence is lacking that students like it more than conventional approaches.

A third approach is the active-learning approach. This active learning approach seems promising because it demonstrated that students learn more under this approach while displaying higher levels of interest. However, as the results of our study suggest, this approach needs to be combined with careful guidance and structure provided by either the teacher or the learning materials or both. For instance, Rotgans and Schmidt (2014) conducted a study in which they compared the extent to which students are interest in a mathematics topic in an active learning classroom vs. a direct instruction classroom. In the active learning condition, students worked on a real-life mathematics problem in small groupsguided by a facilitator who provided a certain degree of structure, whereas the direct instruction group was taught about the same topic by a teacher. Results suggest that the active-learning group reportedsignificantly higher levels of interest and engagement than the direct instruction group. This study was however conducted with primary school students and it still needs to be seen if it can be replicated with higher education students who are exposed to more complex mathematics concepts.

\subsection{Limitations and Future Research}

Finally, as with all studies, the present study has a number of limitations that should be acknowledged. First of all, our qualitative analysis is restricted to only one open-ended question. In order to find out more about the underlying issues with mathematics courses it may be necessary to conduct more detailed focus group studies with students and teachers. In the present study we only received feedback from the students; teachers may be able to provide additional insights in what the precise problems are with mathematics teaching in their courses. It seems also necessary to follow-up with some small-scale experiments to examine which of the three above-mentioned instructional approaches, or a combination of them, such asactive learning, more worksheets, and worked examples may have a beneficial effect on students' mathematics learning and their interest in mathematics courses in general.

\section{References}

Atkinson, R. K., Derry, S. J., Renkl, A., \& Wortham, D. (2000). Learning from examples: Instructional principles from the worked examples research. Review of Educational Research, 70(2), 181-214. http://dx.doi.org/10.3102/00346543070002181

Burns, M. K. (2005). Using incremental rehearsal to increase fluency of single-digit multiplication facts with children identified as learning disabled in mathematics computation. Education and Treatment of Children, 28(3), 237-245.

Byrne, B. M. (2001). Structural equation modeling with Amos: Basic concepts, applications and programming. Mahwah, N.J.: Lawrence Erlbaum Assoc Inc.

Choo, S. S. Y., Rotgans, J. I., Yew, E. H. J., \& Schmidt, H. G. (2011). Effect of worksheet scaffolds on student learning in problem-based learning. Advances in Health Sciences Education, 16(4), 517-528. http://dx.doi.org/10.1007/s10459-011-9288-1

Clements, D. H. (2002). Computers in early childhood mathematics. Contemporary Issues in Early Childhood, 3(2), 160-181. http://dx.doi.org/10.2304/ciec.2002.3.2.2

Cohen, J. (1992). A power primer. Psychological bulletin,
http://dx.doi.org/10.1037/0033-2909.112.1.155 
Freudenthal, H. (1968). Why to teach mathematics so as to be useful. Educational Studies in Mathematics, 1(1), 3-8. http://dx.doi.org/10.1007/BF00426224

Freudenthal, H. (1973). Mathematics as an educational task. Dordrecht: Springer.

Freudenthal, H. (1981). Major problems of mathematics education. Educational Studies in Mathematics, 12(2), 133-150. http://dx.doi.org/10.1007/BF00305618

Gravemeijer, K., \& Doorman, M. (1999). Context problems in realistic mathematics education: A calculus course as an example. Educational Studies in Mathematics, 39(1), 111-129. http://dx.doi.org/10.1023/A:1003749919816

Hancock, G. R., \& Mueller, R. O. (2001). Rethinking construct reliability within latent systems. In R. Cudeck, S. D. Toit, \& D. Sörbom (Eds.), Structural equation modeling: Present and future-A festschrift in honor of Karl Jöreskog (pp. 195-216). Lincolnwood, IL: Scientific Software International.

Hannover, B., \& Kessels, U. (2004). Self-to-prototype matching as a strategy for making academic choices. Why high school students do not like math and science. Learning and Instruction, 14(1), 51-67. http://dx.doi.org/10.1016/j.learninstruc.2003.10.002

Hmelo-Silver, C. E. (2004). Problem-based learning: What and how do students learn? Educational Psychology Review, 16(3), 235-266. http://dx.doi.org/10.1023/B:EDPR.0000034022.16470.f3

Hofman, A., De Jong, U., Van Leeuwen, M., Van den Berg, M., De Boom, J., De Graaf, D., \& Roeveld, J. (2001). Studentenmonitor 2000. Zoetermeer: Ministerie van OCenW.

Manoucherhri, A. (1998). Computers and school mathematics reform: Implications for mathematics teacher education. Journal of computers in mathematics and science teaching, 18(1), 31-48.

Mikkonen, J., Heikkila, A., Ruohoniemi, M., \& Lindblom-Ylanne, S. (2009). "I study because I am interested": University students' explanations for their disciplinary choices. Scandinavian Journal of Educational Research, 53(3), 229-244. http://dx.doi.org/10.1080/00313830902917261

Miller, G. A. (1995). WordNet: A lexical database for English. Journal of the Association for Computing Machinery, 38(11), 39-41. http://dx.doi.org/10.1145/219717.219748

Ormell, C. (1984). How to design a mathematics course which will appeal to the non-specialist pupil. International Journal of Mathematics Education in Science and Technology, 15(3), 299-304. http://dx.doi.org/10.1080/0020739840150305

Renkl, A. (1999). Learning mathematics from worked-out examples: Analyzing and fostering self-explanations. European Journal of Psychology of Education, 14(4), 477-488. http://dx.doi.org/10.1007/BF03172974

Renkl, A. (2002). Worked-out examples: Instructional explanations support learning by self-explanations. Learning and Instruction, 12(5), 529-556. http://dx.doi.org/10.1016/S0959-4752(01)00030-5

Rotgans, J. I., O'Grady, G., \& Alwis, W. A. M. (2011). Introduction: Studies on the learning process in the one-day, one-problem approach to problem-based learning. Advances in Health Sciences Education, 16(4), 443-448. http://dx.doi.org/10.1007/s10459-011-9299-y

Rotgans, J. I., \& Schmidt, H. G. (2014). Situational interest in mathematics: A microanalytical comparison of problem-based learning vs. direct instruction. Submitted for publication.

Salkind, N. J. (2010). Encyclopedia of research design, 1.

Schiefele, U. (1992). Topic interest and levels of text comprehension. In K. A. Renninger, S. Hidi, \& A. Krapp (Eds.), The role of interest in learning and development (pp. 151-182). Hillsdale, NJ: Lawrence Erlbaum Associates.

Schmidt, H. G. (1983). Problem-based learning: Rationale and description. Medical Education, 17(1), 11-16. http://dx.doi.org/10.1111/j.1365-2923.1983.tb01086.x

Schmidt, H. G. (1993). Foundations of problem-based learning: Some explanatory notes. Medical Education, 27(5), 422-432. http://dx.doi.org/10.1111/j.1365-2923.1993.tb00296.x

Schmidt, H. G., Van der Molen, H. T., Te Winkel, W. W. R., \& Wijnen, W. H. F. W. (2009). Constructivist, problem-based, learning does work: A meta-analysis of curricular comparisons involving a single medical school. Educational Psychologist, 44(4), 227-249. http://dx.doi.org/10.1080/00461520903213592 
Schoon, I. (2001). Teenage job aspirations and career attainment in adulthood: A 17-year follow-up study of teenagers who aspired to become scientists, health professionals, or engineers. International Journal of Behavioral Development, 25(2), 124-132. http://dx.doi.org/10.1080/01650250042000186

Sockalingam, N., Rotgans, J. I., \& Schmidt, H. G. (2011). The relationships between problem characteristics, achievement-related behaviors, and academic achievement in problem-based learning. Advances in Health Sciences Education, 16(4), 481-490. http://dx.doi.org/10.1007/s10459-010-9270-3

SPSS. (2006). SPSS Text Analysis for Surveys ${ }^{\mathrm{TM}} 2.0$ user guide. Chicago: SPSS Inc.

SPSS. (2008). Gaining full value from SPSS Text Analysis for Surveys ${ }^{\mathrm{TM}}$. Chicago: SPSS Inc.

Suraweera, F. (1984). Myths about mathematics learning and teaching. International Journal of Mathematics Education in Science and Technology, 15(3), 381-398. http://dx.doi.org/10.1080/0020739840150315

Tarmizi, R. A., \& Sweller, J. (1988). Guidance during mathematical problem solving. Journal of Educational Psychology, 80(4), 424-436. http://dx.doi.org/10.1037/0022-0663.80.4.424

Van der Veen, I., De Jong, U., Van Leeuwen, M., \& Korteweg, J. A. (2005). The development of higher education students' interest in their subject: The case of higher professional education in the Netherlands. Studies in Higher Education, 30(3), 275-289. http://dx.doi.org/10.1080/03075070500095705

Vermetten, Y. J., Lodewijks, H. G., \& Vermunt, J. D. (1999). Consistency and variability of learning strategies in different university courses. Higher Education, 37(1), 1-21. http://dx.doi.org/10.1023/A:1003573727713

Viamonte, A. J. (2010). The computer in the teaching of mathematics. Paper presented at the 6th WSEAS/IASME International Conference in Educational Technology, Tunesia.

Wolters, C., \& Pintrich, P. R. (1998). Contextual differences in student motivation and self-regulated learning in mathematics, English, and social studies classrooms. Instructional Sciences, 26(1-2), 27-47. http://dx.doi.org/10.1023/A:1003035929216

\section{Copyrights}

Copyright for this article is retained by the author(s), with first publication rights granted to the journal.

This is an open-access article distributed under the terms and conditions of the Creative Commons Attribution license (http://creativecommons.org/licenses/by/3.0/). 